\title{
PRODUÇÃO CIENTÍFICA SOBRE RODÍZIO DE AUDITORIA: UMA ANÁLISE BIBLIOMÉTRICA E SOCIOMÉTRICA NAS BASES SCIENSE DIRECT E SCOPUS ${ }^{1}$
}

\author{
SCIENTIFIC PRODUCTION ON ROTATION OF AUDIT: A BIBLIOMETRIC \\ ANALYSIS AND SOCIOMETRIC BASES IN SCIENSE DIRECT AND SCOPUS
}

\author{
Rodrigo Barraco Marassi ${ }^{2}$ \\ Mestrando em Ciência Contábeis pela FURB \\ rodrigomarassi_16@hotmail.com \\ Maria Margarete Brizolla \\ Doutoranda em Ciência Contábeis e Administração pela FURB \\ marga.brizolla@unijui.edu.br \\ Paulo Roberto da Cunha \\ Doutor em Ciências Contábeis e Administração pela FURB \\ Professor do Programa de Pós-Graduação em Ciências Contábeis da FURB \\ Professor da Universidade do Estado de Santa Catarina (UDESC) \\ pauloccsa@furb.br
}

\section{RESUMO}

O estudo objetiva identificar redes sociais sobre o tema rodízio de auditoria nas bases Science Direct e Scopus entre os anos de 1996 e 2012. A presente pesquisa traz como diferenciais tanto a evolução das pesquisas que envolvem o tema "rodízio de auditoria" de 1996 a 2012 quanto a apresentação das redes de produção científica entre autores que trataram desse tema nesse período. O referencial teórico apresentado aborda autores que tratam do rodízio de auditoria. Quanto à metodologia, efetuou-se uma pesquisa sociométrica, empírico-analítica, realizada em 36 periódicos internacionais e 1 periódico nacional de negócios, gestão e contabilidade. Nas bases pesquisadas filtrou-se a expressão "Rotation of audit" no título, resumo e palavras-chave do artigo, em que retornaram 75 artigos, dos quais 5 não estavam relacionados ao tema e 1 se teve acesso somente ao resumo. Logo, a amostra foi composta por 69 artigos. Nestes, realizou-se análise bibliométrica e análise de redes (sociométrica), comparando-se as principais características de redes sob o enfoque de small worlds. Os resultados indicam que as abordagens encontradas com maior recorrência relacionam-se a qualidade da auditoria e a independência de auditores. Destaca-se a necessidade da ampliação no número de artigos publicados, pois ao longo de 17 anos foram encontradas 75 publicações nas bases analisadas. Outro aspecto importante diz respeito ao número de citações das obras analisadas, as quais poderiam ter um impacto mais alto, caracterizando a consolidação do tema como um campo de pesquisa permanente para os pesquisadores. Também utilizou-se a técnica de nuvens de

\footnotetext{
${ }^{1}$ Artigo recebido em: 31/03/2014. Revisado por pares em: 10/04/2014. Recomendado para publicação em: 22/04/2014 por Orleans Silva Martins (Editor Geral). Publicado em: 30/04/2014. Organização responsável pelo periódico: UFPB.

2 Endereço: Rua Antônio da Veiga, 140, Sala C 202, Victor Konder, Caixa Postal 1507, CEP 89012-900, Blumenau/SC. DOI: http://dx.doi.org/10.18405/recfin20140101
} 
palavras, onde verificou-se que a palavra que mais apareceu no estudo foi auditoria, seguida por rotação, auditor e qualidade.

Palavras-chave: Auditoria. Rodízio de Auditoria. Bibliometria. Sociometria. Redes Sociais.

\section{ABSTRACT}

The study aims to identify social networks on the topic castor audit in Science Direct and Scopus databases between the years 1996 and 2012. This research presents as differentials, both the evolution of research involving the theme "Castor audit " from 1996 to 2012, as the presentation of scientific production networks among authors who have treated this subject in this period. The theoretical framework presented covers authors who treat the rodizia audit. Regarding the methodology we performed an analytical - empirical sociometric survey, conducted in 36 international journals and 1 national journal of business, management and accounting. In the surveyed foundations filtered the term "Rotation of audit" in the title, abstract and key words in the article, which returned 75 articles, 5 of which were not related to the topic and only 1 was given access to the summary, then the sample consisted of 69 items. These was held bibliometric analysis and network analysis (sociometric), comparing the main characteristics of networks under the focus of small worlds. The results indicate that the approaches found more recurrences are related to audit quality and independence of auditors, there is the need to expand the number of published articles, for over 17 years 75 publications were found in the databases analyzed. Another important aspect concerns the number of citations of articles analyzed, which could have a higher impact, featuring the consolidation of the subject as a field of ongoing research for researchers. We also used the technique of word clouds, where it was found that the word appeared in the study was more audit followed by rotation, auditor and quality.

Keywords: Audit. Audit Rotation. Bibliometrics. Sociometry. Social Networks.

\section{1}

\section{INTRODUÇÃO}

Os usuários externos de informações contábeis, especialmente no Brasil, necessitam de informações mais detalhadas a respeito das transações executadas pelas organizações nas quais possuem investimentos, a fim de possibilitar melhor interpretação e análise dos dados apresentados (LOPES, 2002). Considerando que estes usuários não têm acesso aos relatórios internos da empresa, de onde derivam as demonstrações contábeis publicadas, entende-se que a auditoria reduz a assimetria de informação existente entre os gestores e os demais interessados na empresa, isto é, os investidores, possibilitando que os usuários que se encontram externos aos limites da empresa acreditem nas demonstrações financeiras (BECKER, et al. 1998). Os investidores exigem dos gestores informações confiáveis, com o intuito de aprimorar suas decisões de investimento com menor grau de risco nos negócios (FARKAS; MURTHY, 2013).

A auditoria em seu papel de agente efetua seu trabalho no intuito de verificar se as demonstrações contábeis estão elaboradas e apresentadas adequadamente, de modo a atender o previsto nas normas e procedimentos contábeis (BOYNTON; JOHNSON; KELL, 2002). Nesse sentido, a evidenciação contábil desempenha uma importante função na divulgação das demonstrações financeiras obrigatórias e recomendadas, em que o enfoque principal da informação contábil é evidenciar de modo objetivo, tempestivo, fidedigno e completo, as informações de natureza quantitativa e qualitativa oriundas das atividades organizacionais (BOFF, 2007; CPC 00, 2010).

Percebe-se também que a auditoria externa pode influenciar nas práticas de evidenciação, em que são observadas que as grandes empresas de auditoria efetuam investimentos maiores na manutenção de sua imagem em relação às pequenas, uma vez que em caso de danos na sua reputação as perdas são maiores. Destaca-se que estas empresas têm maior número de clientes, logo são 
menos dependentes de cada um deles, levando ao maior comprometimento com a qualidade dos serviços prestados (DeANGELO, 1981; AHMED, 1994).

Myers, Myers e Omer (2003) acreditam que quando o auditor possui maior experiência, eles observam com maior acuracidade e restrições o grau de investimento permitidos pela administração. Estes resultados sugerem que o rodízio de auditores pode ter efeitos adversos sobre a qualidade da auditoria, assim como a qualidade da auditoria é menor nos primeiros anos do relacionamento entre auditor e cliente. Ainda, quanto à qualidade, verifica-se que a capacidade dos auditores de serem imparciais em seus julgamentos contribui para a melhoria da qualidade e reside, especialmente, à objetividade dos mesmos como uma dimensão da inerente independência do auditor (TAYLOR; DEZOORT; THOMAS, 2003).

A independência é o alicerce da estrutura filosófica da profissão de auditoria. As opiniões dos auditores independentes terão pouca importância e qualidade para os terceiros que desejarem confiar nos resultados dos pareceres de auditoria, caso os mesmos não sejam além de competentes, independentes e imparciais no seu julgamento da expressão da opinião (BOYNTON; JOHNSON; KELL, 2002).

Assunção e Carrasco (2008) apontam que o rodízio dos auditores é favorável ao mercado nacional, partindo do princípio de que após a mudança na legislação os novos auditores tornam-se mais conservadores e aumentam a probabilidade de emitir ressalvas. Bandyopadhyay, Chen e Yu (2013) mencionam que os efeitos do rodízio obrigatório de auditores são favoráveis para a qualidade da auditoria, pois essa rotação causa variações na concentração do mercado da auditoria e a inserção de um novo sócio de auditoria favorece a eficácia dos serviços prestados.

DeFond e Francis (2005) e Stefaniak, Robertson e Houston (2009) mencionam que a maioria das pesquisas existentes não fornecem evidências para apoiar a introdução do rodízio obrigatório de firmas de auditoria nos Estados Unidos da América (EUA), a fim de ser realmente considerado como um meio para melhorar a qualidade da auditoria. Diante do exposto, questiona-se: como se apresenta a produção científica internacional sobre rodízio de auditoria no período de 1996 e 2012 ? Assim, este estudo objetiva analisar a produção científica internacional sobre rodízio de auditoria no período de 1996 a 2012 por meio de uma análise bibliométrica e sociométrica.

Em termos de estudos internacionais relevantes, aponta-se o realizado por Walker, Lewis e Casterella (2001), ao afirmar que as empresas que adotam a prática voluntária de realizarem o rodízio de auditores acabam por se diferenciar significativamente em uma amostra aleatória de empresas por eles pesquisadas. Especificamente, a análise dos autores sugere que os auditores rotativos evitam que as empresas realizem fraudes e, consequentemente, prejuízos financeiros. Ainda, Beasley e Petroni (2001) levantam hipóteses que tratam da qualidade da contabilidade quando existe a troca de firmas de auditoria.

A presente pesquisa traz como diferenciais tanto a evolução das pesquisas que envolvem o tema "rodízio de auditoria" de 1996 a 2012 quanto a apresentação das redes de produção científica entre autores que trataram desse tema nesse período. Contribuindo para o avanço de pesquisas sobre rodízio de auditores, no que tange a abertura de novas lacunas para explorar esse consistente tema, aborda aspectos da independência do auditor e a efetividade da realização dos trabalhos.

\section{2}

\section{REFERENCIAL TEÓRICO}

A auditoria pode ser considerada uma tecnologia contábil aplicada ao exame dos registros, demonstrações ou elementos de consideração contábil, visando apresentar opiniões, conclusões, críticas e orientações sobre situações ou fenômenos patrimoniais das organizações públicas ou privadas, já ocorridos ou que estejam por ocorrer (SÁ, 2002). A apresentação destas conclusões e opiniões do auditor deve estar pautada, além de no conhecimento técnico acerca do objeto de análise, numa postura de ética e independência do auditor. 
Qualquer que seja o ambiente de atuação do auditor, este deve sempre atentar para a ética e a responsabilidade que lhe cabem enquanto profissional escolhido para realizar a análise das informações contábeis. Uma discussão da independência acerca do auditor independente perpassa pelo rodízio de auditoria, que merece uma diferenciação de rodízio de auditoria e rodízio de auditores.

A Comissão de Valores Mobiliários (CVM) publicou, em novembro de 2011, a Instrução Normativa $n^{0}$ 509, estabelecendo, dentre outros, a possibilidade de as empresas que possuem Comitê de Auditoria Estatutário (CAE) permanente serem auditadas pelo mesmo auditor independente (pessoa jurídica) pelo prazo de até 10 (dez) anos, dobrando o prazo atual do rodízio instituído pela IN/CVM no 308/99.

No entendimento de Costa e Azevedo (2008), os defensores da rotatividade obrigatória de firmas de auditoria argumentam que longos mandatos levam a uma maior intimidade com o cliente, reduzindo a independência. Órgãos reguladores da profissão contábil destacam que a troca da empresa de auditoria periodicamente assegura aos auditores independentes incentivos a não ceder às pressões dos gestores, mantendo o compromisso e comprometimento dos auditores com a independência e ética na execução dos trabalhos de auditoria.

Já Oliveira e Santos (2007) destacam que até mesmo o rodízio de auditores, que não representa necessariamente a rotação das firmas de auditorias, mas sim dos profissionais que a executam, pode apresentar aspectos considerados como positivos ou negativos. Embora, num primeiro momento, mostre-se positivo o rodízio de firma de auditoria ou mesmo de auditores, no Quadro 1 estão abordados aspectos considerados negativos e positivos sobre esta prática.

\section{Quadro 1 - Aspectos negativos e positivos do rodízio.}

a) Não mantém o conhecimento acumulado da firma de auditoria que tem feito os trabalhos. O foco dos trabalhos do novo auditor pode não ser direcionado para áreas de risco;

b) Desestabiliza a relação econômica entre as partes. No primeiro ano de trabalho, é realizado um investimento considerável pelas firmas na expectativa de ser recuperado em anos subsequentes por trabalhos mais eficientes e mais bem planejados;

c) Redução dos investimentos em especialização dos auditores, pois as firmas não alocariam recursos na formação técnica, sem a certeza de que a interrupção do relacionamento ocorreria por circunstâncias normais, e não por decisão regulatória;

d) A governança corporativa é afetada, pois liberdade de escolha estaria sendo impactada em sua essência;

e) Desequilibra o mercado das firmas, pois a busca pela recomposição de carteiras de clientes seria estruturada de forma inadequada, sem respeitar as condições normais de mercado;

f) A carreira em auditoria seria dificultada, pois a perda desses clientes pode propiciar até mesmo a interrupção da prática de auditoria de firmas. a) Socializa o conhecimento técnico, pois quebra o monopólio do conhecimento e da prática de auditoria de determinado segmento;

b) Satisfaz o público com a quebra de relacionamento de longo prazo, conferindo a determinados usuários de demonstrações contábeis uma percepção de maior independência;

c) Muda o perfil do auditor nas empresas submetidas ao rodízio. Um perfil mais técnico do auditor é privilegiado em detrimento do perfil comercial e gerador de novos trabalhos;

d) Requer maior atenção do auditor pelo processo frequente de troca, pela exposição de seus papéis de trabalho a outros auditores, sucessores ou revisores;

e) Focaliza a atenção do auditor no acionista, e não na administração;

f) Muda a metodologia de auditoria com foco concentrado nos procedimentos obrigatórios e maior objetividade na alocação e no foco dos testes de auditoria;

g) Atenua a falta de fiscalização do Estado, pois a possibilidade de o auditor sucessor ter acesso aos papéis de trabalho referentes ao processo de auditoria das demonstrações contábeis das empresas pode ser considerada uma forma de fiscalização adicional, que deveria estar sendo feita pelo Estado.

Fonte: Oliveira e Santos (2007). 
Além de todos os pontos elencados no Quadro 1, é importante observar que cabe ao auditor apresentar em suas atividades a objetividade de suas ações. Muito embora não possa ser plenamente mensurável, esse princípio é indispensável para os que atuam com auditoria independente. Isto porque possuir objetividade significa ser imparcial, ou seja, não ser tendencioso em todas as questões relacionadas a um trabalho de auditoria, em obediência a esse princípio.

Carey e Simnett (2008) corroboram com a visão anterior, ao afirmarem que as empresas adotantes de um rodízio de auditores estão mais aptas a mudar sua gestão de prestação de informações mediante a prestação de serviços de auditores externos com seus pareceres classificados como de alta qualidade. DeFond e Francis (2005) e Stefaniak, Robertson e Houston (2009) concluíram que a maioria das pesquisas existentes não fornecem evidências para apoiar a introdução do rodízio obrigatório de firmas de auditoria nos Estados Unidos da América (EUA), a fim de ser realmente considerado como um meio para melhorar a qualidade da auditoria.

Os resultados reforçam ainda o argumento de que novas auditorias podem ser problemáticas às empresas devido ao efeito gerado pela mudança de visões em suas respectivas curvas de aprendizagem (experiência). A maioria destes estudos estimam modelos de regressão nos quais o processo de auditoria com base no rodízio, associado às diversas medidas de qualidade de auditoria, levam o auditor a introduzir viés de auto seleção para o modelo de revisão nas informações das organizações (GEIGER; RAGHUNANDAN, 2002).

Geiger e Raghunandan (2002) constataram que os auditores são mais propensos a emitir um parecer de auditoria sem ressalvas antes de um pedido de falência de um cliente que nos primeiros anos de relacionamento entre auditor-cliente. Em contrapartida, Myers, Myers e Omer (2003) acreditam que, quando o auditor possui maior experiência, ele observa com maior acuracidade e restrições sobre o grau de investimento permitido pela administração. Estes resultados sugerem que o rodízio de firmas de auditoria obrigatório pode ter efeitos adversos sobre a qualidade da auditoria, assim como a qualidade da auditoria é menor nos primeiros anos do relacionamento entre auditor e cliente.

Ainda, em termos de rotação obrigatória, se um cliente está experimentando conflitos com seu auditor independente sobre tratamentos contábeis e o auditor é obrigado a ser trocado, o mercado perde sinais valiosos, os quais teriam ocorridos no caso de ter sido realizada uma rotação voluntária. As maiores empresas de contabilidade também pode aumentar a sua quota de mercado com base em uma rotação obrigatória, como no caso da Itália (BUCK, MICHAELS; 2005), o que acabou levando às empresas daquele país a um ambiente menos competitivo.

Diante de tais impressões e findada a breve discussão acerca da situação relacionada ao papel do rodízio de auditores, parte-se para o estabelecimento dos procedimentos metodológicos que nortearam o presente artigo.

3

\section{PROCEDIMENTOS METODOLÓGICOS}

Com base no objetivo proposto, realizou-se um estudo descritivo, com abordagem quantitativa e documental como forma de coleta de dados. O estudo concebeu-se numa perspectiva longitudinal que compreende o período de 1996 a 2012, utilizando-se de análise bibliométrica e sociométrica. A pesquisa bibliométrica direciona-se ao estudo dos aspectos quantitativos da produção, disseminação do conhecimento e uso da informação registrada (MACIAS-CHAPULA,1998), enquanto que o estudo sociométrico aprofunda o relacionamento entre os atores que fazem parte dessa rede (GALASKIEWICZ, WASSERMAN; 1994).

Foram selecionados os artigos relacionados ao tema de rodízio de auditoria no âmbito dos trabalhos disponibilizados nas bases Science Direct e Scopus no período de 1996 a 2012. Para tanto, buscou-se os artigos nas bases por meio da expressão "rotation of audit" nos campos título, resumo 
e palavras-chave. Esta busca selecionou 75 artigos, dos quais 5 não estavam relacionados ao tema e 1 foi conseguido somente o resumo do artigo, o que determinou uma amostra de 69 artigos.

Estes 69 artigos estão distribuídos em 37 periódicos: Academy of Accounting and Financial Studies Journal; Accounting and Business Research; Accounting and Finance; Accounting and the Public Interest; Accounting, Auditing and Accountability Journal; Accounting Forum 30; Accounting in Europe; Accounting Horizons; Accounting, Organizations and Society; Accounting Research Journal; Accounting Review; Auditing: A Journal of Practice and Theory; Advances in Accounting; American Accounting Association; Asian Journal of Business and Accounting; Auditing; Business Horizons; Contemporary Accounting Research; Critical Perspectives on Accounting; Current Issues in Auditing; Harvard Business Review; International Business Management; J Betriebswirtsch; J Manag Control; Journal of Accounting and Public Policy; Journal of Accounting, Auditing and Finance; Journal of Accounting Research; Journal of Business Ethics; Journal of Contemporary Accounting and Economics; Journal of International Accounting, Auditing and Taxation; Managerial Auditing Journal; Revista Espanola de Financiacion y Contabilidad; Research in Accounting Regulation; Springer Science, Business Media New York; The British Accounting Review; The International Journal of Accounting; e Revista Brasileira de Gestão de Negócios.

Para identificar a abordagem principal dos artigos, realizou-se a análise de conteúdo citada por Bardin (2002) com foco também no título, resumo e palavras chave dos artigos. No que concerne ao levantamento de dados para as análises bibliométrica e sociométrica, efetuou-se a tabulação dos seguintes itens: período de publicação dos artigos; periódico; identificação dos autores por ano; temas dos artigos; quantidade de citações pela base de dados ISI e Google Acadêmico. Na análise sociométrica, das redes sociais, utiliza-se a exploração das redes de coautoria, a qual representa uma vertente de análise de redes sociais (LIU et al.; 2005). Para gerar as figuras representativas da estrutura da rede e seus indicadores empregou-se o software UCINET® 6.

\section{$4 \quad$ ANÁLISE DOS RESULTADOS}

Nesta seção são apresentadas a descrição e a análise dos resultados encontrados no estudo.

Na Tabela 1, destaca-se o número de artigos analisados por periódico e por período.

Tabela 1 - Número de artigos por periódico e período de análise.

\begin{tabular}{|c|c|c|c|c|c|}
\hline Periódico & $\begin{array}{c}1996 \text { a } \\
2000\end{array}$ & $\begin{array}{c}2001 \text { a } \\
2005 \\
\end{array}$ & $\begin{array}{c}2006 \text { a } \\
2010\end{array}$ & $\begin{array}{c}2011 \text { a } \\
2012 \\
\end{array}$ & Total \\
\hline Academy of Accounting and Financial Studies Journal & & & 1 & & 1 \\
\hline Accounting \& Finance & & & 1 & & 1 \\
\hline Accounting and Business Research & & & & 1 & 1 \\
\hline Accounting and the Public Interest & & & & 1 & 1 \\
\hline Accounting Forum 30 & & & 1 & & 1 \\
\hline Accounting Horizons & & 1 & 3 & 1 & 5 \\
\hline Accounting in Europe & & & & 2 & 2 \\
\hline Accounting Research Journal & & & & 1 & 1 \\
\hline Accounting Review & & 3 & 1 & & 4 \\
\hline Accounting, Auditing and Accountability Journal & & & 1 & & 1 \\
\hline Accounting, Organizations and Society & & & 1 & & 1 \\
\hline Advances in Accounting & & & 4 & & 4 \\
\hline American Accoun. Associa., Current Issues in Auditing & & & & 1 & 1 \\
\hline Asian Journal of Business and Accounting & & & & 1 & 1 \\
\hline Auditing & & 1 & 2 & 2 & 5 \\
\hline Auditing: A Journal of Practice \&Theory & & & 1 & & 1 \\
\hline Business Horizons & & & 1 & & 1 \\
\hline Contemporary Accounting Research & & & 3 & & 3 \\
\hline Critical Perspectives on Accounting & & & 1 & & 1 \\
\hline Current Issues in Auditing & & & & 1 & 1 \\
\hline Harvard Business Review & & & 2 & & 2 \\
\hline International Business Management & & & & 1 & 1 \\
\hline
\end{tabular}


J Betriebswirtsch

J Manag Control

Journal of Accounting and Public Policy

Journal of Accounting Research

Journal of Accounting, Auditing and Finance

Journal of Business Ethics

Journal of Contemporary Accounting \& Economics

Journal of International Accounting, Auditing \& Taxation

Managerial Auditing Journal

Research in Accounting Regulation

Revista Brasileira de Gestao de Negocios

Revista Española de Financiación y Contabilidad

Springer Science, Business Media New York

The British Accounting Review

The International Journal of Accounting

Total

Fonte: Dados da pesquisa.

Verifica-se na Tabela 1 um maior número de publicação no período compreendido entre 2006 a 2010, com 41 publicações. Observa-se que os dois primeiros períodos de análise mantiveram-se homogêneos, com 4 e 6 publicações. O terceiro período, de 2006 a 2010, apresentou um crescimento significativo de publicação sobre o tema. Tal crescimento pode ter sido influenciado após as fraudes contábeis ocorridos nos início do ano de 2000, que envolveram inclusive empresas de auditoria. Tais fatos podem ter colocado em foco a discussão da independência dos auditores e de mecanismos que pudessem contribuir para esta independência, como o rodízio de firmas de auditoria. No último período se observou uma redução na publicação, entretanto, destaca-se o fato deste período compreender somente dois anos. Além da quantidade de artigos por período e periódico, verificou-se na Tabela 2 o número de autores por artigo.

Tabela 2 - Número de autores por artigo.

\begin{tabular}{l|c|c|c|c|c}
\hline Período & 1 Autor & 2 Autores & 3 Autores & > 3 Autores & Total \\
\hline 1996 a 2000 & $1(1,45 \%)$ & $3(4,35 \%)$ & & & $4(5,80 \%)$ \\
2001 a 2005 & $3(4,35 \%)$ & $8(11,59 \%)$ & $3(4,35 \%)$ & & $14(20,29 \%)$ \\
2006 a 2010 & $4(5,80 \%)$ & $10(14,49 \%)$ & $16(23,19 \%)$ & $3(4,35 \%)$ & $33(47,83 \%)$ \\
2011 a 2012 & $2(2,90 \%)$ & $4(5,80 \%)$ & $7(10,14 \%)$ & $5(7,25 \%)$ & $18(26,09 \%)$ \\
\hline Total & $\mathbf{1 0 ( 1 4 , 2 9 \% )}$ & $\mathbf{2 5 ( 3 5 , 7 1 \% )}$ & $\mathbf{2 6 ( 3 7 , 1 4 \% )}$ & $\mathbf{8 ( 1 1 , 4 3 \% )}$ & $\mathbf{6 9 ( 1 0 0 \% )}$ \\
\hline
\end{tabular}

Fonte: Dados da pesquisa.

Destaca-se, na Tabela 2, que a produção científica internacional sobre rodízio de auditoria é concebida por grupos de dois e três autores, com 25 e 26 publicações respectivamente. Há 10 artigos publicados individualmente e 8 em cooperação que apresentam mais de 3 autores. Ainda, busca-se demonstrar como essas redes entre autores se mostraram perante os artigos analisados. Esta análise é efetuada por período, ou seja: 1996 a 2000; 2001 a 2005; 2006 a 2010 e 2011 a 2012. A Figura 1 ilustra as redes de autoria entre 1996 e 2000.

Figura 1 - Rede de autores no período de 1996 a 2000.

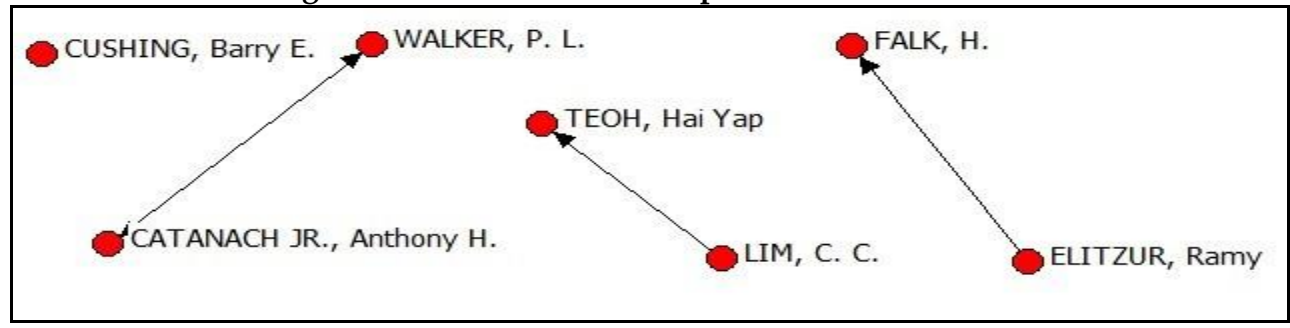

Fonte: Dados da pesquisa. 
Observa-se, na Figura 1, que no primeiro período de análise ocorreram 4 publicações, havendo 3 laços entre os autores Teoh e Lim (1996), Elitzur e Falk (1996) e Catanach Jr e Walker (1999). Entretanto, observa-se a não existência de uma rede densa de autores, provocada pela baixa quantidade de artigos publicados sobre o tema. Ao efetuar uma análise de citações no período, percebe-se que esses trabalhos tiveram citações encontradas apenas no Google Acadêmico e não na base ISI. Vale destacar que na comparação com outros estudos, tais citações não representam alto impacto na produção científica, como visto Teoh e Lim (1996) teve 63 citações; Elitzur e Falk (1996) aparece com 44 citações e Catanach Jr e Walker (1999) com 70 citações.

Na Figura 2, apresenta-se a rede de autores do período compreendido entre 2001 a 2005.

Figura 2 - Rede de autores do período de 2001 a 2005.

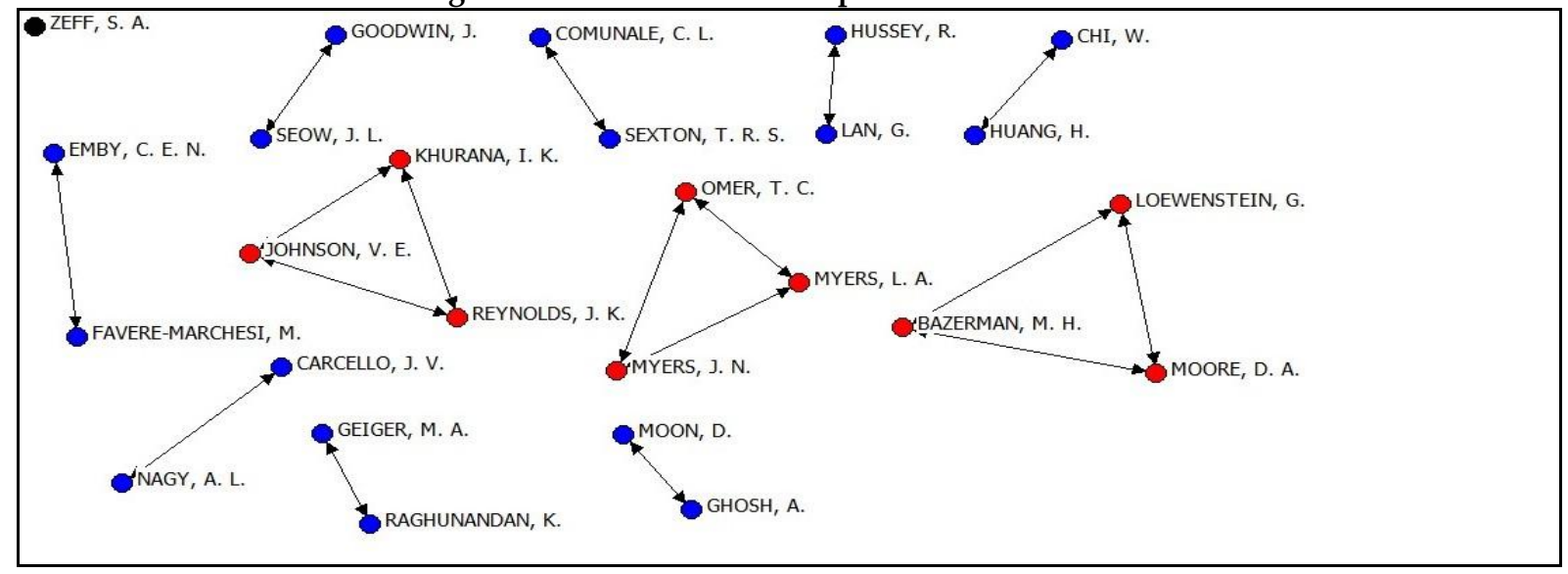

Fonte: Dados da pesquisa.

Nota-se, na Figura 2, que no período compreendido entre 2001 e 2005 a rede de autoria caracteriza-se por sua fragmentação de publicações, apresentando autorias independentes (3 publicações), em díades (8 publicações) e em tríades (3 publicações), com predominância de laços entre 2 autores. Vale destacar que apesar de um número maior de artigos, ainda prevalece a ausência de conexão entre os estudos, o que indica que não há uma rede estabelecida de estudo sobre o tema. Na sequência, apresenta-se o comportamento da rede de coautoria para o período de 2006 a 2010.

Figura 3 - Rede de autores do período de 2006 a 2010.

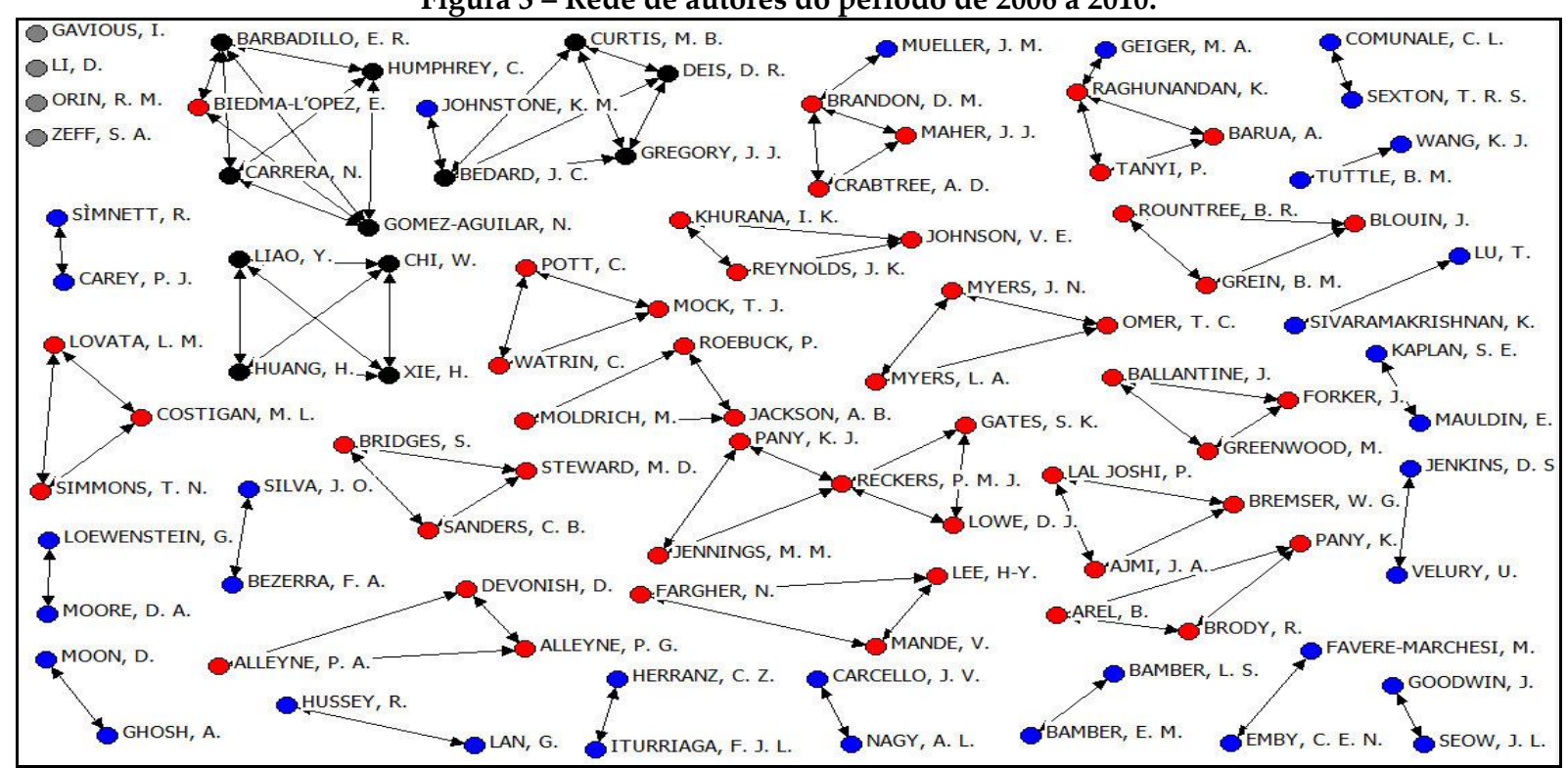

Fonte: Dados da pesquisa. 
De acordo com a Figura 3, no período compreendido entre 2006 e 2010 houve a maior concentração de estudos publicados sobre rodízio de auditoria, com 33 publicações, representando $47,83 \%$ das publicações analisadas. A caracterização da rede de autoria distribui-se em publicações independentes (4 publicações), em díades (10 publicações), em tríades (16 publicações) e com mais de 3 autores tem-se 3 publicações.

Observaram-se pequenas formações de redes de autores. Destaca-se que o período representado na Figura 3 é que apresenta maior concentração de conexões (4 conexões) dentre os analisados. $\mathrm{O}$ fato dos pesquisadores formarem rede conectadas pode caracterizar, apesar de não se poder fazer maiores inferências, mínimas trocas de informações, de modo a caracterizar uma certa potencialidade de formação de capital social na rede (BURT, 1992).

Verifica-se, assim, a existência de pequenas redes estruturais, as quais, de acordo com Burt (1992), fornecem uma vantagem competitiva para o indivíduo que realiza a conexão, uma vez que esse usufrui de acesso às informações dos autores. Esse indivíduo também pode conquistar poder de agenciamento de contato entre os autores aos quais se encontra vinculado.

Na Figura 4, apresenta-se o último período analisado compreendido entre 2011 e 2012. Neste período foram publicados 18 artigos sobre rodízio de auditoria e as relações entre autores apresentam a seguinte configuração: publicações independentes (2); publicações com 2 autores (4); publicações com 3 autores (7); e publicações com mais de 3 autores (5). Nota-se que Firth, Rui e Wu (2012) publicaram neste período 2 artigos intitulados Rotate back or not after mandatory audit partner rotation? e How Do Various Forms of Auditor Rotation Affect Audit Quality? Evidence from China.

Destaca-se uma conexão de grupos de autores, no qual se tem o autor Pevzner $(2011,2012)$ estabelecendo ponte entre os outros 10 componentes. Neste período, observam-se principalmente redes formadas por laços independentes entre si, exceto pela conexão estabelecida Pevzner (2011, 2012), onde esse autor aparece como autor em dois artigos. Esta estrutura corresponde ao que Granovetter (1973) define como laço fraco, ou seja, contatos indiretos formados por meio de pontes, possibilitando maior inovação. Percebe-se a predominância de laços entre 3 autores, seguidos pelos com mais de 3 e 2 autores e das publicações com um autor. Isso mostra a formação de laços fracos entre a rede de autores que publicaram sobre rodízio de auditoria no período.

Figura 4 - Rede de autores do período de 2011 a 2012.

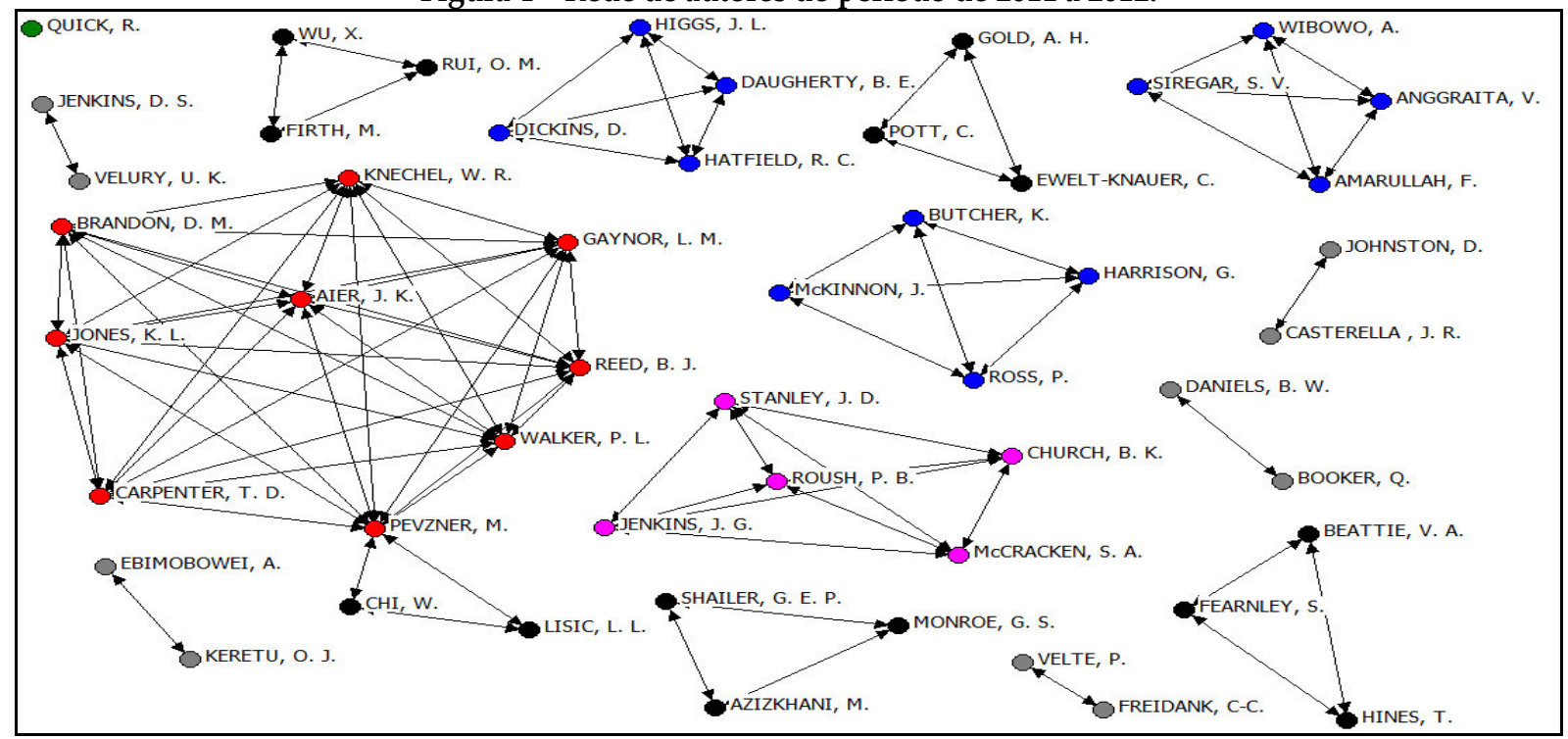

Fonte: Dados da pesquisa.

Nota-se na Tabela 3 que o autor com maior número de laços foi Pevzner, com 10 laços e duas publicações. Por outro lado, têm-se autores com uma única publicação e 8 laços de cooperação e 
autores com 3, 2 e 1 publicações, com 4 e 3 laços. Isto caracteriza um baixo grau prolífico da produção, ou seja, autores publicaram um único trabalho sobre rodízio de auditorias ao longo do período de análise (1996 a 2012).

Tabela 3 - Autores mais prolíficos e com maior número de laços.

\begin{tabular}{|c|c|c|c|c|c|c|c|}
\hline Autor & Artigos & Laços & Participação (\%) & Autor & Artigos & Laços & Participação (\%) \\
\hline PEVZNER, M. & 2 & 10 & 2,86 & CURTIS, M. B. & 1 & 3 & 0,86 \\
\hline AIER, J. K. & 1 & 8 & 2,29 & DEIS, D. R. & 1 & 3 & 0,86 \\
\hline BRANDON, D. M. & 1 & 8 & 2,29 & GREGORY, J. J. & 1 & 3 & 0,86 \\
\hline CARPENTER, T. D. & 1 & 8 & 2,29 & HUANG, $\mathrm{H}$. & 2 & 3 & 0,86 \\
\hline GAYNOR, L. M. & 1 & 8 & 2,29 & HUMPHREY, C. & 1 & 3 & 0,86 \\
\hline JONES, K. L. & 1 & 8 & 2,29 & LIAO, Y. & 1 & 3 & 0,86 \\
\hline KNECHEL, W. R. & 1 & 8 & 2,29 & RAGHUNANDAN, K. & 2 & 3 & 0,86 \\
\hline REED, B. J. & 1 & 8 & 2,29 & XIE, H. & 1 & 3 & 0,86 \\
\hline WALKER, P. L. & 1 & 8 & 2,29 & AMARULLAH, F. & 1 & 3 & 0,86 \\
\hline BARBADILLO, E. R. & 3 & 4 & 1,14 & ANGGRAITA, V. & 1 & 3 & 0,86 \\
\hline BEDARD, J. C. & 2 & 4 & 1,14 & BUTCHER, K. & 1 & 3 & 0,86 \\
\hline GOMEZ-AGUILAR, N. & 3 & 4 & 1,14 & DAUGHERTY, B. E. & 1 & 3 & 0,86 \\
\hline RECKERS, P. M. J. & 2 & 4 & 1,14 & DICKINS, D. & 1 & 3 & 0,86 \\
\hline CHURCH, B. K. & 1 & 4 & 1,14 & HARRISON, G. & 1 & 3 & 0,86 \\
\hline JENKINS, J. G. & 1 & 4 & 1,14 & HATFIELD, R. C. & 1 & 3 & 0,86 \\
\hline McCRACKEN, S. A. & 1 & 4 & 1,14 & HIGGS, J. L. & 1 & 3 & 0,86 \\
\hline ROUSH, P. B. & 1 & 4 & 1,14 & McKINNON, J. & 1 & 3 & 0,86 \\
\hline STANLEY, J. D. & 1 & 4 & 1,14 & ROSS, P. & 1 & 3 & 0,86 \\
\hline BRANDON, D. M. & 2 & 3 & 0,86 & SIREGAR, S. V. & 1 & 3 & 0,86 \\
\hline CARRERA, N. & 2 & 3 & 0,86 & WIBOWO, A. & 1 & 3 & 0,86 \\
\hline CHI, W. & 3 & 3 & 0,86 & & & & \\
\hline
\end{tabular}

Fonte: Dados da pesquisa.

Por fim, tem-se a Tabela 4, que apresenta os indicadores relacionados à rede de cooperação entre autores.

Tabela 4 - Indicadores da rede de cooperação entre autores por período.

\begin{tabular}{|c|c|c|c|c|c|}
\hline Dados Observados na Rede & 1996 a 2000 & 2001 a 2005 & 2006 a 2010 & 2011 a 2012 & TOTAL \\
\hline Pesquisadores (n) & $\begin{array}{l}7 \\
\end{array}$ & 26 & 97 & 51 & 181 \\
\hline Laços & 6 & 36 & 85 & 84 & 211 \\
\hline Número médio laços da rede $(\mathrm{k})$ & 0,857 & 1,385 & 0,876 & 1,647 & 1,166 \\
\hline Numero de componentes & 4 & 12 & 33 & 14 & 63 \\
\hline Tamanho Componente Principal & 2 & 3 & 5 & 11 & 21 \\
\hline Tamanho 2o. maior componente & - & 2 & 4 & 5 & 11 \\
\hline Unidades Isoladas & 1 & 1 & 4 & 1 & 7 \\
\hline Densidade & 0,0952 & 0,0523 & 0,0195 & 0,0682 & 0,059 \\
\hline Centralização & $3,33 \%$ & $3 \%$ & $1,82 \%$ & $6,86 \%$ & 0,038 \\
\hline Distância média & 1 & 1 & 1,131 & 1,160 & 1,073 \\
\hline Coeficiente de agrupamento & 1 & 1 & 1,031 & 1,066 & 1,024 \\
\hline \multicolumn{6}{|l|}{ Dados Aleatórios } \\
\hline Coeficiente de agrupam. rede esperado (k/n) & 0,122 & 0,053 & 0,009 & 0,032 & 0,054 \\
\hline PL: Distância Média Esperada [ln(n)/ln(k)] & $-12,623$ & 10,012 & $-34,641$ & 7,880 & $-7,343$ \\
\hline \multicolumn{6}{|l|}{ Indicadores } \\
\hline PL taxa (PL real / PL aleatório) & $-0,079$ & 0,100 & $-0,033$ & 0,147 & 0,034 \\
\hline CC taxa (CC real/CC aleatório) & 8,167 & 18,778 & 114,126 & 33,008 & 43,520 \\
\hline Q: Coef. Small World (CC taxa/PL taxa) & $-0,010$ & 0,005 & 0,000 & 0,004 & 0,000 \\
\hline
\end{tabular}

Fonte: Dados da pesquisa.

No período pesquisado (1996 a 2012), analisou-se 69 artigos publicados sobre o tema e 181 pesquisadores/autores. Isso evidencia crescimento tanto no número de artigos como de pesquisa- 
dores, o período inicial (1996 a 2000) de 6 laços, o segundo período (2001 a 2005) com 36 laços, o terceiro período (2006 a 2010) com 85 e o final (2011 a 2012) de 84 laços. A média de colaboração foi de 1,166 laços por pesquisador no período final. Esse indicador cresceu ao longo do período analisado, sendo que no período de 1996 a 2000, o número médio de laços por autor foi de 0,857, havendo 1 unidade isolada de publicação e um total de 7 pesquisadores no período.

Para o período de 2001 a 2005, a média de colaboração dos autores foi de 1,385 laços, com 1 unidade isolada de publicação, havendo um aumento significativo no número de pesquisadores (30). Nota-se no terceiro período (2006 a 2010) que a média de colaboração dos autores foi de 0,876 laços, com 3 unidades isoladas de publicação, havendo um aumento significativo no número de pesquisadores (49). Para o último período de análise (2011 a 2013), verifica-se que a média de colaboração dos autores foi de 1,647 laços, com 1 unidade isolada de publicação e o número de pesquisadores foi de 51, menos pesquisadores envolvidos que no período anterior. No entanto, ressaltase que para este período foram analisados 3 anos, enquanto que nos demais cada período compreendeu 5 anos de análise.

Identificou-se, na Tabela 4, que a densidade da rede foi de 0,095 no período 1996 a 2000; de 0,052 no período 2001 a 2005; de 0,020 no período 2006 a 2010; e de 0,068 no período 2011 a 2013. A possibilidade média de um determinado ator estar ligado a outro foi baixa, característica também observada em estudos sociométricos similares de Lazzarini (2007), Rossoni e Guarido Filho (2009), Dal Vesco, Santos e Scarpin (2010), Fernandes, Dal Vesco e Walter (2011) e Dal Vesco e Beuren (2012). Os coeficientes de agrupamentos, ficaram entre 1 e 1,066, considerados alto se comparado ao esperado que foi de 0,009 a 0,122 para a quantidade de artigos analisados, apontando para a existência de grupos coesos, mesmo sendo pequenos.

Verifica-se, ainda, que os períodos analisados (1996 a 2000, 2001 a 2005, 2006 a 2010 e 2011 a 2012) agruparam no componente principal 2, 3, 5 e 11 pesquisadores/autores respectivamente, como já mencionado, no qual os autores que centralizam as publicações são Gomez-Aguilar, Barbadillo, Bedard, Reckers e Pevzner.

A Figura 5 mostra os componentes principais da rede, de acordo com os respectivos períodos de publicação dos artigos.

Figura 5 - Rede de coautoria entre autores - Componentes principais (1996 a 2000).

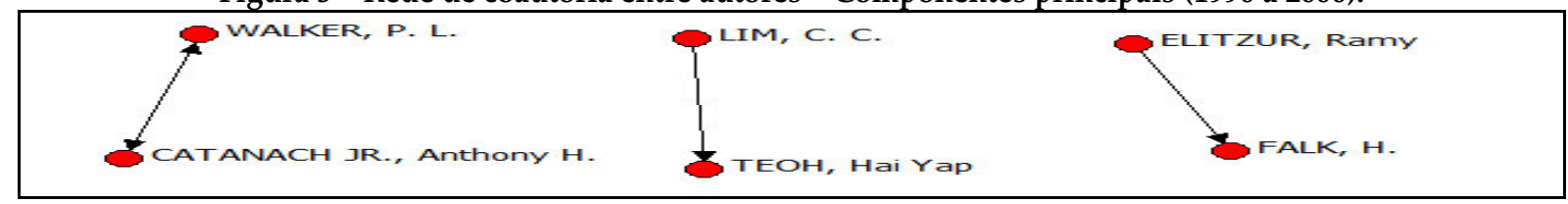

2001 a 2005
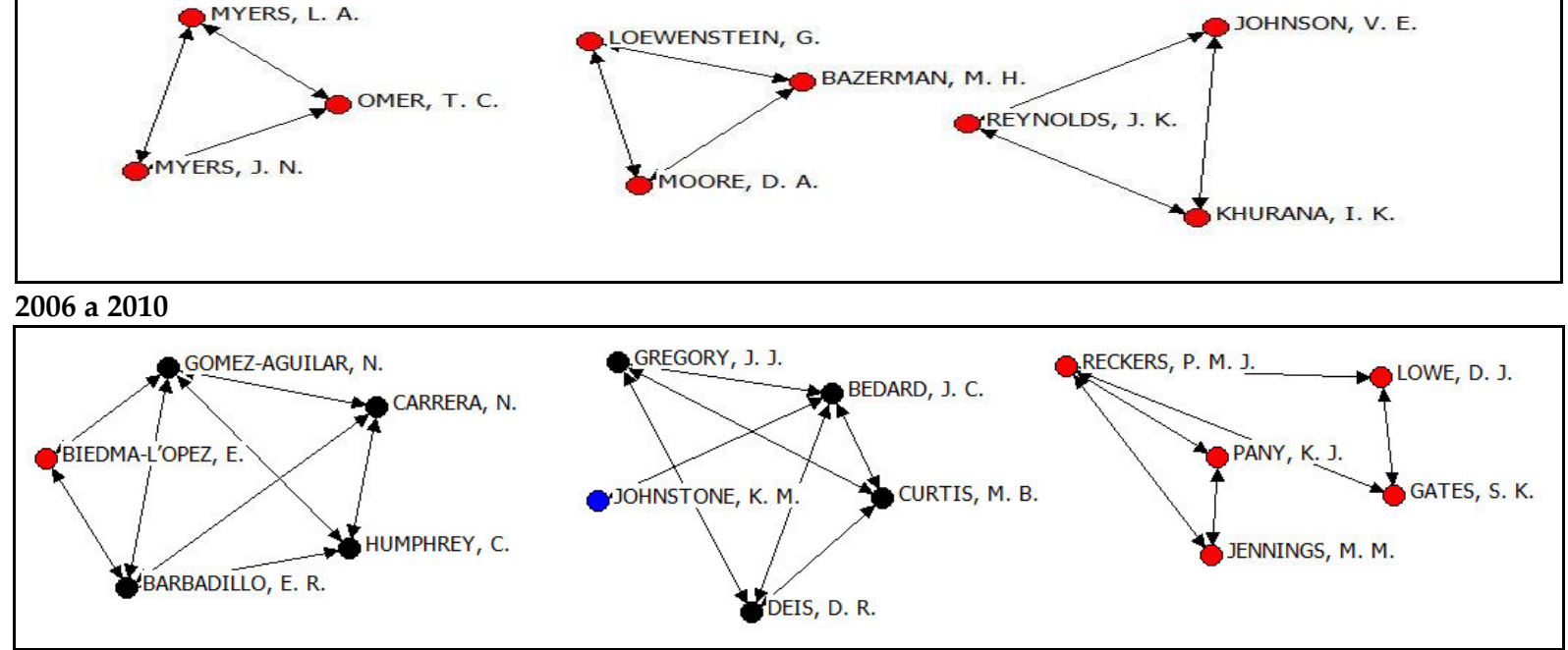


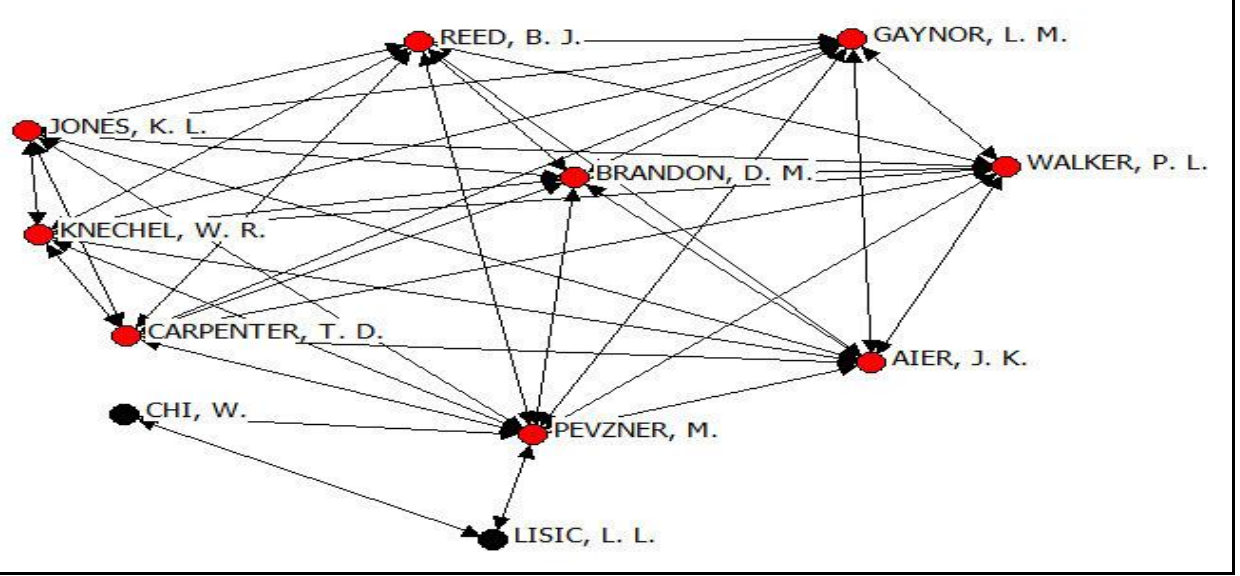

Fonte: Dados da pesquisa.

Os pesquisadores sobre o tema rodízio de auditoria nos artigos analisados mostram não estarem estruturalmente próximos um dos outros. Por exemplo, levando em consideração a distância média entre os pesquisadores no componente principal, é observado que eles necessitam, em média, de 1 a 1,16 intermediários para alcançar qualquer pesquisador dentro do próprio componente. Tal configuração das relações, alinhada ao elevado coeficiente de agrupamento (entre 1 e 1,066, próximos de 1) indica a ocorrência de agrupamentos com maior densidade nas relações. Fatores que podem explicar tal comportamento são a imersão institucional e a localidade dos pesquisadores verificados nos resultados obtidos nos estudos de Rossoni e Graeml (2009).

Pelas premissas apontadas no modelo de Watts e Strogatz (1998), que identificam baixa densidade total, densidade local muito superior e distância média similar, como características de redes do tipo mundos pequenos, a rede analisada se apresenta estruturada como um small world.

Na sequência, a Tabela 5 apresenta o número de citações por artigo publicado. Optou-se por elencar os artigos acima de 50 citações. Ressalta-se, no entanto, que dos 69 artigos analisados, 8 ainda não foram citados. Desses 8 artigos, 6 foram publicados em 2012, 1 em 2011 e 1 em 2005.

Tabela 5 - Quantidade de citações por artigo.

\begin{tabular}{l|l|l|c|c|c}
\hline \multicolumn{1}{c|}{ Título } & \multicolumn{1}{c|}{ Autor } & Co-autores & Ano & ISI & $\begin{array}{c}\text { Google } \\
\text { Acadêmico }\end{array}$ \\
\hline $\begin{array}{l}\text { Exploring the term of the auditor-client } \\
\text { relationship and the quality of earnings: } \\
\text { A case for mandatory auditor rotation? }\end{array}$ & MYERS, J. N. & $\begin{array}{l}\text { MYERS, L. A. } \\
\text { OMER, T. C. }\end{array}$ & 2003 & NA & 638 \\
\hline $\begin{array}{l}\text { Audit-Firm Tenure and the Quality of } \\
\text { Financial Reports }\end{array}$ & JOHNSON, V. E. & $\begin{array}{l}\text { KHURANA, I. K. } \\
\text { REYNOLDS, J. K. }\end{array}$ & 2002 & 70 & 392 \\
\hline $\begin{array}{l}\text { Auditor tenure and perceptions of audit } \\
\text { quality }\end{array}$ & GHOSH, A. & MOON, D. & 2005 & 55 & 350 \\
\hline $\begin{array}{l}\text { Auditor tenure and audit reporting fail- } \\
\text { ures }\end{array}$ & GEIGER, M. A. & RAGHUNANDAN, K. & 2002 & 41 & 322 \\
\hline $\begin{array}{l}\text { Audit Firm Tenure and Fraudulent Fi- } \\
\text { nancial Reporting }\end{array}$ & CARCELLO, J. V. & NAGY, A. L. & 2004 & 42 & 273 \\
\hline $\begin{array}{l}\text { Why good accountants do bad audits } \\
\text { Audit partner tenure and audit quality }\end{array}$ & BAZERMAN, M. H. & $\begin{array}{l}\text { LOEWENSTEIN, G. } \\
\text { MOORE, D. A. }\end{array}$ & 2002 & 33 & 270 \\
\hline $\begin{array}{l}\text { Mandatory audit firm turnover, financial } \\
\text { reporting quality, and client bargaining } \\
\text { power: The case of arthur andersen }\end{array}$ & NAGY, A. L. & SIMNETT, R. & 2006 & 50 & 260 \\
\hline $\begin{array}{l}\text { An analysis of forced auditor change: The } \\
\text { case of former Arthur Andersen clients }\end{array}$ & BLOUIN, J. & $\begin{array}{l}\text { GREIN, B. M. } \\
\text { ROUNTREE, B. R. }\end{array}$ & 2007 & 25 \\
\hline
\end{tabular}




\begin{tabular}{l|l|l|c|c|c}
\hline $\begin{array}{l}\text { Discretionary Accruals, Audit-Firm Ten- } \\
\text { ure and Audit-Partner Tenure: Empirical } \\
\text { Evidence from Taiwan }\end{array}$ & CHI, W. & HUANG, H. & 2005 & NA & 74 \\
\hline $\begin{array}{l}\text { The International Debate Over Mandato- } \\
\text { ry Auditor Rotation: A Conceptual Re- } \\
\text { search Framework }\end{array}$ & CATANACH JR., A. H. & WALKER, P. L. & 1999 & NA & 70 \\
\hline $\begin{array}{l}\text { An empirical study of the effects of audit } \\
\text { committees, disclosure of nonaudit fees, } \\
\text { and other issues on audit independence: } \\
\text { Malaysian evidence }\end{array}$ & TEOH, H. Y. & LIM, C. C. & 1996 & NA & 63 \\
\hline $\begin{array}{l}\text { Mandatory Audit Partner Rotation, Audit } \\
\begin{array}{l}\text { Quality, and Market Perception: Evidence } \\
\text { from Taiwan }\end{array}\end{array}$ & CHI, W. & $\begin{array}{l}\text { HUANG, H. } \\
\text { LIAO, Y. } \\
\text { XIE, H. }\end{array}$ & 2009 & 10 & 63 \\
\hline $\begin{array}{l}\text { Risk monitoring and control in audit } \\
\text { firms: A research synthesis }\end{array}$ & BÉDARD, J. C. & $\begin{array}{l}\text { DEIS, D. R. } \\
\text { CURTIS, M. B. } \\
\text { GREGORY, J. J. }\end{array}$ & 2008 & 10 & 47 \\
\hline
\end{tabular}

Fonte: Dados da pesquisa. Nota: NA - Não aplica.

Na Tabela 5, destaca-se que o primeiro artigo sobre rodízio de auditoria, de Myers, Myers e Omer (2003), pela base de dados ISI, não foi encontrado (NA) e pelo Google Acadêmico atingiu 638 citações. Verifica-se que o artigo de Blouin, Grein e Rountree (2007) aparece com 25 citações na base ISI e 88 no Google Acadêmico. Já a obra de Ghosh e Moon (2005) aparece com 55 citações na ISI e 350 citações no Google, enquanto a obra de Carcello e Nagy (2004) teve 42 citações na ISI e 273 citações no Google e, ainda, em 2002, dois artigos tiverem destaque em citações, um de autoria de Johnson, Khurana e Reynolds (2002), com 70 citações na ISI e 392 citações no Google e outro com 33 citações na ISI e 270 no Google, de autoria de Bazerman, Loewenstein e Moore (2002). Os demais artigos apresentam menos de 50 citações.

Após, apresenta-se a análise das abordagens dadas ao tema rodízio de auditoria, evidenciados na Tabela 6.

Tabela 6 - Temas associados ao rodízio de auditoria.

\begin{tabular}{l|c}
\hline \multicolumn{1}{c|}{ Tema } & Artigos \\
\hline Qualidade da auditoria & 23 \\
Independência dos auditores & 19 \\
Qualidade da auditoria e Independência dos auditores & 6 \\
Custos com o rodízio de auditoria & 3 \\
Padrões éticos, independência dos auditores e rodízio de auditoria & 3 \\
Custos e qualidade da Auditoria e independência dos Auditores & 2 \\
Efeitos de obrigatoriedade do rodízio de auditoria nas decisões de Investimentos & 2 \\
O gerenciamento de resultados e o rodízio de auditoria & 2 \\
Atributos ambientais afetam o rodízio de auditoria & 2 \\
Impacto do rodízio de auditoria nas negociações com os clientes & 2 \\
Perda do conhecimento em razão do rodízio de auditoria & 1 \\
Modificação no relatório de auditoria em razão do rodízio de auditoria & 1 \\
Política de apresentação de evidências de Auditoria e rodízio de auditoria & 1 \\
Efeito do rodízio de auditoria no critério contábil usado pelos clientes & 1 \\
Efeito do conselho de administração e do comitê de auditoria na decisão de mudar de auditor & 1 \\
\hline Total de Artigos & 69 \\
\hline
\end{tabular}

Fonte: Dados da pesquisa.

Nota-se, na Tabela 6, que foram identificados 15 abordagens distintas para o tema rodízio de auditoria dentre os artigos pesquisados. Percebe-se que a abordagem mais recorrente nas obras analisadas é o relacionado à qualidade da auditoria com 23 artigos. Para Church e Zhang (2007) o relacionamento longo entre auditor e cliente é prejudicial para a qualidade da auditoria. 
A segunda abordagem dada ao tema refere-se à independência dos auditores, com 19 obras encontradas. A capacidade dos auditores de serem imparciais em seus julgamentos reside, especialmente, à objetividade dos mesmos como uma dimensão da inerente independência do auditor (TAYLOR; DEZOORT; THOMAS, 2003). Ainda foram identificados 6 artigos que abordam a qualidade da auditoria e a independência dos auditores.

A Tabela 7 apresenta os dez autores mais referenciados nos artigos, o número de vezes que os autores foram citados no corpo do texto e a quantidade de obras distintas (livros, artigos e outros) que aparecem nos artigos da amostra. Além dos autores indicados na Tabela 7, mais 302 autores foram referenciados ao menos uma vez nos artigos. O número mínimo e máximo ficou entre 1 a 71 referências para os não inclusos na tabela.

Tabela 7 - Autores mais referenciados.

\begin{tabular}{|c|c|c|c|c|c|c|c|}
\hline \multirow[b]{2}{*}{ Autor } & \multicolumn{2}{|c|}{ Citações } & \multicolumn{2}{|c|}{ Referências } & \multirow[b]{2}{*}{$\begin{array}{c}\text { Distintas } \\
\text { Obras }\end{array}$} & \multirow{2}{*}{$\begin{array}{c}\text { Relação entre } \\
\text { Citações e Obras } \\
\text { Citadas }\end{array}$} & \multirow[b]{2}{*}{$\begin{array}{c}\text { Relação entre Citações e } \\
\text { Referências Citadas }\end{array}$} \\
\hline & Qtde. & Ranking & Qtde. & Ranking & & & \\
\hline 1 Myers & 168 & $1^{\underline{o}}$ & 39 & $1^{o}$ & 2 & 84,00 & 4,31 \\
\hline 2 Francis & 155 & $2^{\mathrm{o}}$. & 38 & $2^{o}$ & 3 & 51,67 & 4,08 \\
\hline 3 Chi & 118 & $3^{\mathrm{o}}$. & 22 & $10^{\circ}$. & 7 & 16,86 & 5,36 \\
\hline 4 Chen & 116 & $4^{\circ}$. & 25 & $7^{\circ}$ & 6 & 19,33 & 4,64 \\
\hline 5 Lin, C. J & 114 & $5^{\mathrm{o}}$. & 24 & $8^{\circ}$. & 5 & 22,80 & 4,75 \\
\hline 6 Lin, Y. C. & 113 & $6^{\circ}$. & 24 & 9 ㅇ. & 5 & 22,60 & 4,71 \\
\hline 7 Raghunandan & 111 & $7^{\circ}$. & 33 & $5^{\circ}$. & 2 & 55,50 & 3,36 \\
\hline 8 Johnson & 110 & $8^{\circ}$. & 38 & $3^{\circ}$. & 2 & 55,00 & 2,89 \\
\hline 9 DeAngelo & 102 & 9o. & 34 & $4^{\circ}$. & 3 & 34,00 & 3,00 \\
\hline 10 DeFond & 92 & $10^{\circ}$. & 26 & $6^{\circ}$. & 2 & 46,00 & 3,54 \\
\hline
\end{tabular}

Fonte: Dados da pesquisa.

Nota-se, na Tabela 7, que o autor mais citado e referenciado nos artigos analisados foi Myers, na $1^{\underline{a}}$ colocação em quantidade de citações e de referências, seguido por Francis na $2^{\underline{a}}$ colocação em citações e em referências. Já os autores que mais produziram obras diferentes dentre os analisados foram Chi (7), Chen (6) e Lin C. J. e Lin Y. C. (5).

\section{CONCLUSÃO}

Este estudo objetivou analisar a produção científica internacional sobre rodízio de auditoria por meio de uma análise bibliométrica e sociométrica entre os anos de 1996 e 2012. Pesquisou-se nas bases Science Direct e Scopus e foram analisada uma amostra de 69 artigos.

Os resultados da pesquisa mostram que o número de artigos publicados e a densidade das redes de cooperação vêm se ampliando no decorrer dos 18 anos investigados, o que reforça a evolução do tema de rodízio de auditoria. No entanto, percebe-se que o número de artigos é baixo e a estrutura das redes é fragmentada se comparado a estudos realizados sobre outros temas, como Walter e Silva (2008), Rocha, Walter, Silva e Gimenez (2011), mas similar aos estudos de Fernandes, Dal Vesco e Walter (2011) e Dal Vesco e Beuren (2012). Pode-se inferir que esse resultado tenha ocorrido em razão de o estudo estar centrado a um tema específico, limitando-se às publicações listadas nas bases Science Direct e Scopus e a busca pela expressão "rotation of audit" no título, resumo e palavras chave do artigo.

No que se refere à baixa densidade das redes de autoria, observa-se que os autores de artigos relacionados ao tema rodízio de auditoria dão preferência a publicações em díades e tríades (26 publicações). Percebem-se poucas publicações desses autores sobre o tema, contudo, pela análise das citações na base de dados da ISI e Google Acadêmico, observou-se um impacto razoável da produção cientifica. O resultado indicam que a obra de Myers, Myers e Omer (2003) teve um bom número de citações (698), no entanto, entende-se ser necessário melhorar o impacto na produção 
científica, caracterizando-o como um tema de pesquisa permanente para os pesquisadores. Percebe-se que as abordagens encontradas com maior recorrência na análise sobre o tema rodízio de auditoria foram as relacionadas a qualidade da auditoria e a independência de auditores, sendo assim, para o desenvolvimento do conhecimento, seria interessante o desenvolvimento de estudos com abordagens diversificadas, propiciand o o amadurecimento dos pesquisadores sobre este tema e o contato com outros pesquisadores, estimulando a realização de parcerias.

Com base nos resultados da pesquisa, conclui-se que a produção científica nas bases Science Direct e Scopus sobre o tema rodízio de auditoria nas áreas de negócios, gestão e contabilidade está se desenvolvendo, entretanto, destaca-se a necessidade da ampliação no número de artigos publicados, pois ao longo de 17 anos foram encontradas 75 publicações nas bases analisadas (69 artigos compuseram a amostra) o que poderia contribuir para a melhoria da densidade de suas relações. Outro aspecto importante analisado no estudo relaciona-se ao número de citações das obras que compuseram a amostra e a identificação dos autores e obras mais citados, os as quais poderiam ter um impacto mais alto, caracterizando a consolidação do tema como um campo de pesquisa permanente para os pesquisadores.

\section{REFERÊNCIAS}

AHMED, K. D. N. The Impact of Non-financial Company Characteristics on Mandatory Disclosure Compliance in Developing Countries: The Case of Bangladesh. The International Journal of Accounting Education and Research, v. 29, p. 62-77, 1994.

BANDYOPADHYAY, S. P.; CHEN, C.; YU, Y. Mandatory audit partner rotation, audit market concentration, and audit quality: Evidence from China. Advances in Accounting, 2013.

BARDIN, L. Análise de conteúdo. Lisboa: Edições 70, 2002.

BAZERMAN, M. H.; LOEWENSTEIN, G.; MOORE, D. A. Why good accountants do bad audits. Harvard business review, v. 80, n. 11, p. 96-103, 2002.

BEASLEY, M. S.; PETRONI. K. Board independence and audit firm type. Auditing: A Journal of Practice \& Theory, v. 20, n. 1, p. 97-114, march, 2001.

BECKER, C. L.; DEFOND, M. L.; JIAMBALVO, J.; SUBRAMANYAM, K. R. The effect of audit quality on earnings management. Contemporary Accounting Research, v. 15, Spring, p. 1-24, 1998.

BLOUIN, J.; GREIN, B. M.; ROUNTREE, B. R. An analysis of forced auditor change: The case of former Arthur Andersen clients. The Accounting Review, v. 82, n. 3, p. 621-650, 2007.

BOFF, M. L. Estratégias de legitimidade organizacional de Lindblom na evidenciação ambiental e social em relatórios da administração de empresas familiares. 2007. 161 f. Dissertação (Mestrado em Ciências Contábeis) - Universidade Regional de Blumenau, Blumenau-SC, 2007.

BOYNTON, W C.; JOHNSON, R.; KELL, W. G. Auditoria. São Paulo: Atlas, 2002.

BUCK, T.; MICHAELS, A. Doubts cast on mandatory rotation of auditors. Financial Times, v. 10, p. 21, 2005. 
BURT, R. S. The social structure of competition. Networks and organizations: Structure, form, and action, v. 57, p. 91, 1992.

CARCELLO, J. V.; NAGY, A. L. Audit firm tenure and fraudulent financial reporting. Auditing: A Journal of Practice \& Theory, v. 23, n. 2, p. 55-69, 2004.

CAREY, P. J.; SIMNETT, M. Costs Associated With Going-Concern-Modified Audit Opinions: An Analysis of the Australian Audit Market. Abacus, v. 44, n. 1, p. 61-81, 2008.

CATANACH JR, A. H.; WALKER, P. L. The international debate over mandatory auditor rotation: A conceptual research framework. Journal of International Accounting, Auditing and Taxation, v. 8, n. 1, p. 43-66, 1999.

CHURCH, B., ZHANG, P.. Auditor Rotation, Financial Reporting Quality, and Auditor Tenure. Working Paper, Georgia Institute of Technology and University of Toronto. 2007.

COSTA, F. M.; AZEVEDO, F. Efeito da troca da firma de auditoria no gerenciamento de resultados das companhias abertas brasileiras. Disponível em: http://www.anpcont.com.br/site/docs/congressoII/02/CUE373.pdf. Acesso em: 13 Abr. 2013.

COMISSÃO DE VALORES MOBILIÁRIOS - CVM. Instrução CVM Noo 308. Disponível em:

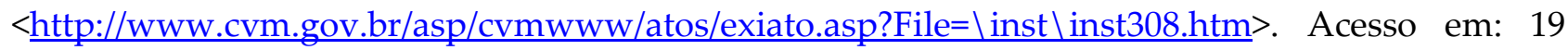
Abr. 2013.

COMITÊ DE PRONUNCIAMETOS CONTÁBEIS - CPC. CPC 00 (R1) - Estrutura conceitual para elaboração e divulgação de relatório contábil-financeiro, 2010. Disponível em: http://www.cpc.org.br/index.php. Acesso em: 05 nov. de 2013.

DAL VESCO, D. G.; MACHADO, D. G.; SCARPIN, J. E. Cooperação entre os capitais sociais em empresas Concessionárias de Serviços Públicos no Brasil: evidências estruturais em concessões de rodovias. In: EnANPAD, 34. Anais... Rio de Janeiro, 2010.

DAL VESCO, D. G.; BEUREN, I. Teoria da estrutura de propriedade: redes sociais em periódicos internacionais de alto impacto. Revista Facultad de Ciencias Económicas: Investigación y Reflexión, v. 20, n. 1, 2012.

DeANGELO, L. E. Auditor independence, low balling, and disclosure regulation. Journal of Accounting and Economics, n. 3, p. 133-127, 1981.

DEFOND, M. L.; FRANCIS, J. R. Audit research after Sarbanes-Oxley. Auditing: A Journal of Practice $\mathcal{E}$ Theory, v. 24, n. s-1, p. 5-30, 2005.

ELITZUR, R.; FALK, H. Planned audit quality. Journal of Accounting and Public policy, v. 15, n. 3, p. 247-269, 1996.

FARKAS, M.; MURTHY, U. S. Nonprofessional investors' perceptions of the incremental value of continuous auditing and continuous controls monitoring: An experimental investigation. International Journal of Accounting Information Systems, 2013. 
FERNANDES, F. C.; DAL VESCO, D. G.; WALTER, S. A. Redes sociais em teoria da decisão: uma análise do campo das produções cientificas nacionais. In: SIMPOI, São Paulo. Anais... São Paulo: FGV, 2011.

FIRTH, M.; RUI, O. M.; WU, X. How do various forms of auditor rotation affect audit quality? Evidence from China. Evidence from China, 2012.

GALASKIEWCZ, J.; WASSERMAN, S. Advances in social network analysis: research in the social and behavioral sciences. London: Sage. 1994.

GEIGER, M. A.; RAGHUNANDAN, K. Auditor tenure and audit reporting failures. Auditing: A Journal of Practice E Theory, v. 21, n. 1, p. 67-78, 2002.

GHOSH, A.; MOON, D. Auditor tenure and perceptions of audit quality. The Accounting Review, v. 80, n. 2, p. 585-612, 2005.

GRANOVETTER, M. The strength of weak ties. American journal of sociology, v. 78, n. 6, p. 1, 1973.

JOHNSON, V. E.; KHURANA, I. K.; REYNOLDS, J. K. Audit-Firm Tenure and the Quality of Financial Reports. Contemporary accounting research, v. 19, n. 4, p. 637-660, 2002.

LAZZARINI, S. G. Mudar tudo para não mudar nada: análise da dinâmica de redes de proprietários no brasil como mundos pequenos. RAE-eletrônica, v. 6, n. 1, 2007.

LIU, X.; BOLLEN, J.N.; MICHAEL, L.; VAN DE SOMPEL, H. Co-authorship networks in the digital library research community. Information processing \& management, v. 41, n. 6, p. 1462-1480, 2005.

LOPES, A. B. A informação contábil e o mercado de capitais. São Paulo: Thomson, 2002.

MACIAS-CHAPULA, C. A. O papel da informetria e da cienciometria e sua perspectiva nacional e internacional. Ciência da informação, v. 27, n. 2, p. nd-nd, 1998.

MYERS, J. N.; MYERS, L. A.; OMER, T. C. Exploring the term of the auditor-client relationship and the quality of earnings: A case for mandatory auditor rotation?. The Accounting Review, v. 78, n. 3, p. 779-799, 2003.

OLIVEIRA, A. Q.; SANTOS, N. M. B. F. Rodízio de firmas de auditoria: a experiência brasileira e as conclusões do mercado. Revista Contabilidade E Finanças, v. 18, n. 45, p. 91-100, 2007.

ROSSONI, L.; GUARIDO, E. R. FILHO. Cooperação entre programas de pós graduação em administração no Brasil: evidências estruturais em quatro áreas temáticas. Revista de Administração Contemporânea, v. 13, n.3, 366-390, 2009.

ROSSONI, L.; GRAEML A. L. A. Influência da imersão institucional e regional na cooperação entre pesquisadores do campo da Administração da Informação do Brasil. In: EnADI, Curitiba. Anais... Rio de Janeiro: ANPAD. 2009 
SÁ, A. L. Curso de auditoria. 10 ed. - São Paulo: Atlas, 2002.

STEFANIAK, C. M.; ROBERTSON, J. C.; HOUSTON, R. W. The causes and consequences of auditor switching: A review of the literature. Journal of Accounting Literature, v. 28, p. 47, 2009.

TAYLOR, M. H, DEZOORT, E. M, e THOMAS, M.W (2003). Uma proposta de quadro Enfatizando a Confiabilidade do Auditor sobre independência dos auditores. Horizontes Contábeis, 17 p, 257266.

TEOH, H. Y.; LIM, C. C. An empirical study of the effects of audit committees, disclosure of nonaudit fees, and other issues on audit independence: Malaysian evidence. Journal of International Accounting, Auditing and Taxation, v. 5, n. 2, p. 231-248, 1996.

WALKER, P. L.; LEWIS, B. L.; CASTERELLA, J. R. Mandatory auditor rotation: arguments and current evidence. Accounting Enquiries, v. 10, n. 2, p. 209-242, 2001.

WATTS, D. J.; STROGATZ, S. H. Collective dynamics of 'small-world'networks. Nature, v. 393, n. 6684, p. 440-442, 1998. 